\section{Terrorism, war, and global air traffic}

\section{Jurgen Brauer and J. Paul Dunne}

$\mathrm{O}$ its website, the International Air Transport Association (IATA), a business group, publishes summary data on airline traffic and other variables. Figure 1 is taken from IATA. The bold line reflects seasonally adjusted data for international scheduled passenger traffic and shows sharp declines in revenuepassenger kilometers flown (RPK) in the second half of 2001 as well as in the first half of 2003. At first sight, this could reflect, respectively, the 11 September 2001 ("9/11") terror event and the combat phase of the Iraq war (20 March to 1 May 2003). But the latter event was completely overlaid by a pandemic threat caused by the appearance in Asia and consequent rapid global spread of Severe Acute Respiratory Syndrome (SARS), lasting from November 2002 through July 2003. Consequently, the apparent drop in RPKs flown might be due to either, or both, events. Freight traffic also appears to have been affected, although not in the same degree. In both cases, it is possible that the apparent effects on the airline industry do not stem so much from violence (terror and war) as from third factors such as pandemics, natural catastrophes, or financial crises. The possible effects of the world financial crisis of 2008/9, for example, would seem clearly visible in Figure 1.

Nonetheless, in the months after 9/11, the global airline industry lamented the billions of dollars of losses on account of the event. Air traffic appeared to have dropped sharply, beyond what might be explained by seasonality alone. While airline companies were struggling financially before the attack, it seems that their prospects worsened significantly following it, and some major airlines declared bankruptcy, e.g., Sabena in 2001 and Air Canada in 2003.

The purpose of this article is to revisit the effects, if any, of large-scale violent events, such as terror and war, on global air traffic for the top-20 airlines in the world (by 2007 revenue), while accounting for potential confounding factors. ${ }^{1}$

\section{Brief review of extant literature}

Within the academic literature, Ito and Lee (2005a; 2005b) measure the effect of the impact of 9/11 on domestic U.S. and international airline traffic, respectively. In both cases, they use aggregate data obtained from the U.S. Air Transport Association, the Association of European Airlines, and government organizations such as those in Canada and Australia. Using revenue-passenger kilometers (RPKs) - except for Australia, where the authors use the number of passengers flown - they find a statistically significant adverse impact of 9/11 on air traffic but argue that this effect was quite subtle and complex. For example, travelers' responses depended on risk perceptions, and these varied across countries. Marked changes were already taking

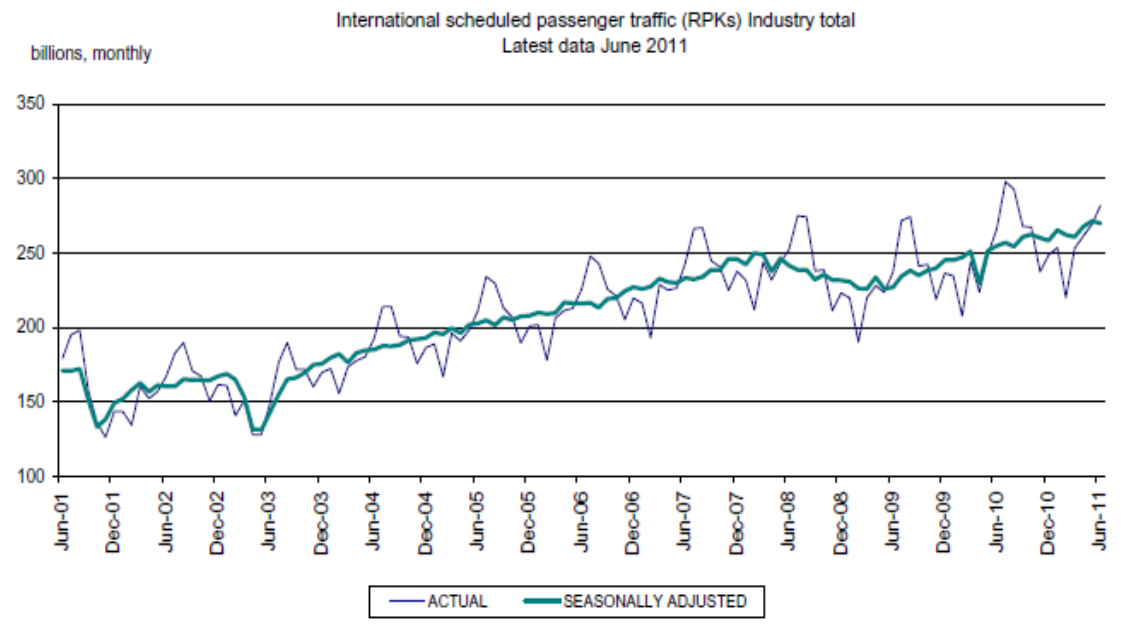

Figure 1: Revenue passenger kilometers (RPK) for international scheduled passenger traffic, June 2001 to June 2011, industry total.

Source: IATA (2011). See http://www.iata.org/whatwedo/economics/Pages/ traffic_analysis.aspx [accessed 10 September 2011].

place in the industry, for instance, industry-wide restructuring and a number of high profile bankruptcies, so that it proved difficult statistically to distinguish the 9/11effect from these other developments. Liu and Zeng (2007) used annual aggregate industry data obtained from the Air Transport Association of America and Airsafe.com to estimate traffic models for U.S. airlines. The use of annual data does rather limit their model's ability of picking up shock effects. The authors find that increases in fatality rates do tend to reduce the demand for air travel but that the 9/11related increase in fatalities does not explain all of the subsequently observed fall in air traffic. Rupp, et al. (2005) examine airline schedule recoveries after U.S. airport closures and find the resulting flight outcomes difficult to explain. ${ }^{2}$

Overall, the impact of 9/11 on the industry does appear unprecedented, but there is in fact no clarity over how it has affected airline traffic. The event created some fear of flying, to be sure, but also led to the introduction of more rigorous security measures at airports, which by themselves may have reduced traffic. Passengers could have moved to "safer" airlines, so that non-U.S. international air traffic may have benefitted. Because of such potentially offsetting responses to 9/11, its effect on global air traffic, if any, is an empirical rather than theoretical question. The extant studies tend to find that 9/11 does not fully explain the subsequent decline in air traffic at the time. Moreover, measured effects appear to have been relatively shortterm in duration.

Our study is novel in several ways. It employs a new, unique air traffic dataset; it 
examines airlines beyond the United States; it includes measures beyond revenuepassenger kilometers (RPK); it employs data with monthly rather than annual frequency; and it controls for (1) terror and war, (2) pandemics, (3) financial shocks, and (4) natural catastrophes on the global airline industry, specifically on international scheduled air traffic. ${ }^{3}$ In what follows we discuss our data, present the results of our models with respect to the top-20 global airlines, and discuss size effects- the estimated magnitude of the effect of the relevant factors on airline performance. The final section concludes and is followed by endnotes and references.

Data

International scheduled airline traffic

We acquired data from the International Civil Aviation Organization (ICAO), an organization of the United Nations system. ${ }^{4}$ The data cover monthly traffic-related statistics for all ICAO member airlines in the world, with records for some airlines going back several decades. In the event, we used monthly data from January 1980 to December 2007. The indicators for airline traffic used are aircraft kilometers flown (ak), number of passengers carried (pc), passenger load factor in percent (plf), and weight load factor in percent (wlf). The load factors are actual passenger and weight traffic measured as a percentage of available capacity to carry passengers and weight.

Although we include the weight carried variable (cargo traveling with passenger aircraft), on the whole we focus on understanding the monthly passenger volume of international scheduled airline traffic. ${ }^{5}$ We focus on passenger volume because this may help to isolate factors that may influence passenger airline traffic, the airlines' major revenue earner. Because airlines can countermand fluctuations in passenger volume with pricing, studying airline revenue is not a modeler's first-choice approach to studying the industry. In addition, the choice of focusing on the volume variable is also dictated by the data in that airline financials are available on an annual basis only whereas the nature of the problem we study often involves single-day episodes that cannot be expected to affect airline traffic across the whole of a year, and, depending on the specific event, may not even affect them over the whole of a month.

Terror events data

For our purposes, the well-known ITERATE database (Enders and Sandler, 2012) suffered from one crucial shortcoming in that it focuses on transnational terror alone. At first sight, this may seem entirely sufficient for a study of international scheduled passenger air traffic. But domestic terror attacks in Egypt (Cairo), India (New Dehli), Norway (Oslo), Spain (Basque country), or the United States (Oklahoma City, Oklahoma), may affect international scheduled passenger air traffic from and to these locations and thus it seemed important to obtain data on domestic terror as well. The
University of Maryland's Global Terrorism Database (GTD) contains a day-by-day record of over 87,000 coded domestic and transnational terror events worldwide, but with the detailed data for 1993 missing. An aggregate figure for 1993, however, was available, and we estimated the monthly data for 1993 using a statistical procedure.

Data issues with ICAO and GTD

Severe data quality problems were encountered with both the ICAO and GTD data. ${ }^{6}$ The Global Terrorism Database (GTD) for example codes over 87,000 terror eventsrecording some 200,000 killed and 245,000 injured victims of terror attacks-but it does not distinguish between domestic and transnational events. Given the variables in GTD and the coding criteria employed, there is no immediately obvious way to effect such separation ourselves. ${ }^{7}$ Also, there is no simple way to extract data according to characteristics that might have been of interest for the purpose of our study. For example, the Madrid train bombing of 11 March 2004 might have affected all international airlines_-not just, say, Iberia-flying scheduled service to and from that city. Coded as six separate events in GTD, the perpetrators are identified as the Abu Hafs al-Masri Brigades. Yet it is unclear whether this was a "domestic" or "transnational" terror event. In fact, it is not even clear that the group ever existed.

Proceeding on the assumption that both the overall number of terror events and the magnitude of the mayhem caused affect general airline traffic more than does any specific event, location, and magnitude, we worked with four different measures of terror: (1) the total number of terror incidents, (2) victims wounded, (3) victims killed, and (4) the number of total casualties (wounded or killed).

\section{Control variables}

Security-related factors other than incidents of terror may shock the global airline industry, and for this reason dummy variables were constructed for the 1991 Persian Gulf war, the 9/11 terror event, and the 2003 Iraq war. That is, we code one especially prominent terror event as well as two prominent wars. To control for economic factors of airline passenger traffic, our preference would have been to employ some measure of output such as monthly GDP data. But countries do not report GDP monthly. Instead, monthly unemployment rates-commonly used as a measure of economic health in such situations-were collected from the Organization for Economic Cooperation and Development (OECD). Available as from January 1980 for the countries that provide the bulk of international air traffic, these data were added to the dataset. The U.S. unemployment rate was used as an indicator of the global business cycle and of changes in global air traffic. (When unemployment is high in the U.S., this usually means that both the United States and the world economy are in recession.)

Financial shocks_-such as Wall Street’s Black Monday in October 1987, the 
Asian financial crisis that began in July 1997 in Thailand, or the bursting of the "dot com” bubble in the U.S. as from March 2000-may also have adversely affected passenger airline demand. Thus, we used unemployment rates as a measure of the global business cycle (earned-income effect) and employed information based on the S\&P500 index to capture financial shocks (wealth effect). Specifically, if monthly changes in the S\&P500 index exceeded $+/-10 \%$, we coded the corresponding month as a shock, not unlike our coding of the 9/11 terror event and the two wars.

The Severe Acute Respiratory Syndrome (SARS) pandemic is a different matter. Even though the death toll was small, news media attention given to the outbreak and the behavioral response that followed may well have affected global air traffic. The Centers for Disease Control and Prevention (CDC) in Atlanta, GA, USA, and the World Health Organization (WHO) in Geneva, Switzerland, list a number of severe pandemic outbreaks: For example, a Hong Kong flu in 1968/69 is estimated to have killed one million people worldwide. The effect on air travel, if any, will come through news media amplification such as was the case for the SARS pandemic threat. While the list of epidemics is long and while these might have regional effects, pandemics today are few a number and are, with rare lapses such as SARS, mostly threats that are quickly handled via CDC/WHO. We therefore coded only the SARS outbreak in our dataset. (The H1N1 outbreak in 2009 lies outside our time frame of 1980-2007.)

Analysis of the top-20 passenger airline companies

Estimating a model for the panel of the top-20 airlines using the logarithm of air kilometers flown (ak) as the dependent variable and total terror events as the indicator of terrorist threat (the "incidence" variable) gives the results summarized in Table 1. Values that are statistically significant are indicated with an asterisk and are set in bold typeface.

The results suggest that the growth of airline kilometers flown is a function of past levels of traffic (lak1), adverse changes in the S\&P500 index (drop10), a one-time negative shock of the 9/11 attack (d911), an upward-pointing trend (ym)—which captures factors such as population and average income growth-and a handful of seasonality variables (s1, s2, s3, s5, s7, s9, and s11) relative to December. Neither the number of terror incidents, nor the unemployment proxy or the wars or the pandemic variable showed anything close to statistical significance. Moreover, the S\&P500 variable is of the "wrong” sign, indicating that air traffic would increase following a ten-percentage point or more drop in the index.

A similar set of estimations was undertaken on the alternative measures of air traffic and terror. Results are reported in Table 2 where the variables marked by an asterisk and bold typeface are statistically significant. (For convenience, we ignore the coefficient signs and also the 11 seasonal variables as they are not germane to the issues at hand here.) The first block of rows ("by incidents") relates the four traffic
Table 1: Top-20 global airlines, monthly for 1980-2007

Dependent variable: Change in log of kilometers flown (dlak)

$\begin{array}{llcc}\text { Independent variables } & \text { Var. } & \text { Coeff. } & \text { t-value } \\ \text { *Lagged log of kilometers flown } & \text { *lak1 } & \mathbf{- 0 . 2 0 4} & -27.5 \\ \text { Change in log incidents } & \text { dlinc } & -0.001 & -0.1 \\ \text { Log of incidents lagged } & \text { linc1 } & -0.002 & -0.2 \\ \text { Change in log of U.S. unemployment } & \text { dluus } & -0.188 & -1.2 \\ \text { U.S. unemployment lagged } & \text { luus1 } & -0.015 & -0.4 \\ \text { SARS } & \text { sars } & -0.001 & 0.0 \\ \text { *S\&P500 10\% decline } & \text { drop10 } & \mathbf{0 . 0 8 6} & \mathbf{2 . 7} \\ \text { S\&P500 10\% increase } & \text { inc10 } & -0.008 & -0.2 \\ \text { *Dummy for 9/11 } & \text { *d911 } & \mathbf{- 0 . 0 6 2} & -3.8 \\ \text { Iraq war dummy } & \text { diraq } & -0.01 & -0.2 \\ \text { Gulf war dummy } & \text { dgulf } & 0.014 & 0.5 \\ \text { *Trend } & \text { *ym } & \mathbf{0 . 0 0 1} & \mathbf{1 3 . 2} \\ \text { Months (seasonality) } & \text { *s1 } & \mathbf{0 . 4 1} & \mathbf{2 . 3} \\ & \text { *s2 } & \mathbf{- 0 . 8 1} & -\mathbf{4 . 5} \\ & \text { *s3 } & \mathbf{0 . 0 9 3} & \mathbf{5 . 1} \\ & \text { s4 } & -0.003 & -0.2 \\ & \text { *s5 } & \mathbf{0 . 0 4 9} & \mathbf{2 . 7} \\ & \text { s6 } & 0.014 & 0.8 \\ & \text { *s7 } & \mathbf{0 . 0 4 1} & \mathbf{2 . 3} \\ \text { *Constant } & \text { s8 } & 0.021 & 1.2 \\ & \text { *s9 } & \mathbf{- 0 . 0 4 9} & -2.7 \\ & \text { s10 } & 0.031 & 1.7 \\ \text { *s11 } & \mathbf{- 0 . 0 4 6} & -\mathbf{2 . 5} \\ & \text { *cons } & \mathbf{3 . 1 1 2} & \mathbf{2 2 . 7}\end{array}$

measures (aircraft kilometers; passengers carried; passenger load factor; and weight load factor) to terror measured by the total number of terror incidents, so that the first column is a shortened version of Table 1 . In blocks 2, 3, and 4, the exercise is repeated except that the measure of terror is changed, respectively, from the number of total terror incidents to the number of people killed in terror attacks, the number wounded in such attacks, and the total number of casualties on account of terror attacks (wounded and killed).

While the variables in the first block do not seem to much explain airline traffic as measured by the logarithm of the absolute indicators of kilometers flown (ak) or 
Table 2: Top-20 global airlines; results for different specifications

$\begin{array}{llll}\text { Aircraft } & \text { Passengers } & \text { Passenger } & \text { Weight } \\ \text { kilometers } & \text { carried } & \text { load factor } & \text { load factor } \\ \text { (dlak) } & (\text { dlpc }) & (\text { dlplf }) & \text { (dlwlf) }\end{array}$

Block 1: by incidents

$\begin{array}{llll}\text { *lak1 } & \text { *lpc1 } & \text { *lplf1 } & \text { *lwlf1 } \\ \text { dlinc } & \text { dlinc } & \text { dlinc } & \text { dlinc } \\ \text { linc1 } & \text { linc1 } & \text { linc1 } & \text { linc1 } \\ \text { dluus } & \text { dluus } & \text { dluus } & \text { *dluus } \\ \text { luus1 } & \text { luus1 } & \text { *luus1 } & \text { *luus1 } \\ \text { sars } & \text { sars } & \text { sars } & \text { sars } \\ \text { *drop10 } & \text { *drop10 } & \text { drop10 } & \text { drop10 } \\ \text { inc10 } & \text { inc10 } & \text { *inc10 } & \text { *inc10 } \\ \text { *d911 } & \text { *d911 } & \text { *d911 } & \text { *d911 } \\ \text { diraq } & \text { *diraq } & \text { *diraq } & \text { *diraq } \\ \text { dgulf } & \text { dgulf } & \text { *dgulf } & \text { *dgulf } \\ \text { *ym } & \text { *ym } & \text { *ym } & \text { ym }\end{array}$

$\begin{array}{clll}\begin{array}{c}\text { Block 2: by killed } \\ \text { *lak1 }\end{array} & \text { *lpc1 } & \text { *lplf1 } & \text { *lwlf1 } \\ \text { dlkill } & \text { dlkill } & \text { dlkill } & \text { dlkill } \\ \text { lkill1 } & \text { *lkill1 } & \text { *lkill1 } & \text { lkill1 } \\ \text { dluus } & \text { dluus } & \text { dluus } & * \text { dluus } \\ \text { luus1 } & \text { luus1 } & \text { *luus1 } & * \text { luus1 } \\ \text { sars } & \text { sars } & \text { sars } & \text { sars } \\ \text { *drop10 } & * \text { drop10 } & \text { drop10 } & * \text { drop10 } \\ \text { inc10 } & \text { inc10 } & \text { *inc10 } & \text { *inc10 } \\ \text { *d911 } & \text { d911 } & * \text { d911 } & * \text { d911 } \\ \text { diraq } & * \text { diraq } & * \text { diraq } & * \text { diraq } \\ \text { dgulf } & \text { dgulf } & * \text { dgulf } & * \text { dgulf } \\ \text { *ym } & * \text { ym } & * \text { ym } & \text { ym }\end{array}$

passengers carried (pc), they do seem somewhat more helpful in explaining the relative air traffic measures, that is, passenger and weight load factors (plf and wlf, respectively). For example, in column 3, the growth in passenger load factor across the 20 airlines for our monthly data from 1980 to 2007 would appear to depend on system inertia (the lagged value of plf), the lagged value of U.S. unemployment, an increase in the S\&P500 index, 9/11, the two wars, and the overall trend variable. At
Table 2: (continued)

$$
\begin{array}{llll}
\text { Aircraft } & \text { Passengers } & \text { Passenger } & \text { Weight } \\
\text { kilometers } & \text { carried } & \text { load factor } & \text { load factor } \\
\text { (dlak) } & (\text { dlpc }) & (\text { dlplf }) & (\text { dlwlf })
\end{array}
$$

Block 3: by wounded

$\begin{array}{llll}\text { *lak1 } & \text { *lpc1 } & \text { *lplf1 } & \text { *lwlf1 } \\ \text { dlwound } & \text { dlwound } & \text { dlwound } & \text { dlwound } \\ \text { lwound1 } & \text { lwound1 } & \text { lwound1 } & \text { lwound1 } \\ \text { dluus } & \text { dluus } & \text { dluus } & \text { *dluus } \\ \text { luus1 } & \text { luus1 } & \text { *luus1 } & \text { *luus1 } \\ \text { sars } & \text { sars } & \text { sars } & \text { sars } \\ \text { *drop10 } & \text { *drop10 } & \text { drop10 } & \text { *drop10 } \\ \text { inc10 } & \text { inc10 } & \text { *inc10 } & \text { *inc10 } \\ \text { *d911 } & \text { *d911 } & \text { *d911 } & \text { *d911 } \\ \text { diraq } & \text { *diraq } & * \text { diraq } & * \text { diraq } \\ \text { dgulf } & \text { dgulf } & * \text { dgulf } & * \text { dgulf } \\ \text { *ym } & * \text { ym } & * \text { ym } & \text { ym }\end{array}$

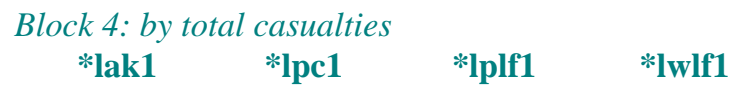

dlcasualties dlcasualties dlcasualties dlcasualties

lcasualties1 lcasualties1 *Icasualties1lcasualties1

dluus dluus dluus *dluus

luus1 luus1 *luus1 *luus1

sars sars sars sars

$\begin{array}{llll}* \text { drop10 } & * \text { drop10 } & \text { drop10 } & \text { *drop10 } \\ \text { inc10 } & \text { inc10 } & \text { *inc10 } & \text { *inc10 }\end{array}$

*d911 *d911 *d911 *d911

diraq *diraq $*$ diraq $*$ diraq

dgulf dgulf *dgulf $*$ dgulf

*ym $\quad *^{\text {ym }} \quad *_{\mathrm{ym}} \quad \mathrm{ym}$

least at first sight, this appears to be a reasonable result.

Interestingly, the statistical results are nearly perfectly consistent across the four blocks of rows: Regardless of which measure of terror is employed, in each case the models pick out the same explanatory variables as statistically significant, or not. Moreover, the results are also nearly perfectly consistent between the two absolute measures of air traffic and the two relative measures. 
When we examined the results for individual airlines, rather than for the panel of all of the top-20 jointly, we found a considerable amount of heterogeneity among the carriers. To deal with this, the base model was estimated using the random coefficient method. This involved estimating separate equations for each of the 20 airlines and then computing the mean for each of the relevant coefficients. The distribution of the means provides the standard errors within which the true, but unknown, coefficients are expected to lie.

The results, shown in Table 3, are remarkably similar to the fixed-effect results (Table 1 ) with the coefficient on the lagged dependent variable (lak1) close to -0.2 , and significant for 17 of the 20 airlines. (The bolded lines in Table 3 do not indicate statistical significance; instead, they highlight those variables that are statistically significant for 10 or more of the 20 airlines, that is, for half or more of our sample.) Except for drop10, which had the "wrong” sign in Table 1, the same variables are significant, namely lak1, d911, and the trend, ym. Moreover, the three statistically significant coefficients in Table 3 are identical in sign and very similar in magnitude to those of Table 1. From a statistical point of view, all this is somewhat reassuring.

Also in Table 3, the GTD data for the number of terror events per se (incidents) add virtually no explanatory power to the number of airline kilometers flown for each of the top-20 global airlines, 1980 to 2007 . The only consistently significant security effect is the $9 / 11$ event, yet even this is statistically significant for just 10 of the top-20 airlines (and 7 of the 20 are North American). Instead, airline traffic as measured by air kilometers seems to be determined as an autoregressive process (that is, inertia) around a trend with seasonal dummies, with the odd shock specific to individual airlines and the more general impact of 9/11. This suggests that 9/11 was an aberration or, alternatively, that it takes an event as massive as 9/11 to shock global airline traffic, as measured by aircraft kilometers flown.

Re-estimating the other variants of the model gives the results displayed in Table 4 (where _x_ stands for the other terror measures, killed, wounded, all casualties). Consistent with the kilometers flown indicator, only the 9/11 event appears relevant among the shock variables. Everything else appears determined by inertia, trend, and seasonality. Although perhaps a surprising result, this is welcomed for its message of statistical consistency.

When the exercise of Tables 3 and 4 is repeated for passenger load factor (plf) rather than air kilometers (ak), the following variables are statistically significant for 10 or more of the 20 airlines: Inertia (that is, lagged plf), lagged U.S. unemployment, a 10\% increase in the S\&P500 index, and the trend and seasonality variables. The four terror and two war measures are statistically significant only for between 6 to 8 airlines, never more than that. Economics trumps security. Once more, this result points to considerable heterogeneity in the sample of the top-20 airlines. It appears that it may be inappropriate to lump rather diverse airlines into a single sample.
Table 3: Random coefficient model results, top-20 global airlines

Change in log of kilometers flown

$\begin{array}{llcl}\text { Var. } & \text { \#sig } & \text { Mean } & \text { St.Dev. } \\ & & & \\ \text { lak1 } & \mathbf{1 7} & \mathbf{- 0 . 1 8 4} & \mathbf{0 . 1 9 9} \\ \text { dlinc } & 2 & 0.000 & 0.013 \\ \text { linc1 } & 4 & -0.003 & 0.022 \\ \text { dluus } & 7 & -0.074 & 0.267 \\ \text { luus1 } & 2 & -0.005 & 0.091 \\ \text { dsars } & 1 & -0.001 & 0.088 \\ \text { drop10 } & 1 & 0.074 & 0.117 \\ \text { inc10 } & 4 & -0.003 & 0.101 \\ \text { d911 } & \mathbf{1 0} & \mathbf{- 0 . 0 5 6} & \mathbf{0 . 1 0 1} \\ \text { diraq } & 1 & -0.023 & 0.067 \\ \text { dgulf } & 1 & -0.001 & 0.039 \\ \text { ym } & \mathbf{1 5} & \mathbf{0 . 0 0 1} & \mathbf{0 . 0 0 2}\end{array}$

Lagged log of kilometers flown

Change in log incidents

Log of incidents lagged

Change in log of U.S. unemployment

U.S. unemployment lagged

Dummy for SARS

Dummy for S\&P500 10\% decline

Dummy for S\&P500 10\% increase

Dummy for $9 / 11$

Dummy for Iraq war

Dummy for Persian Gulf war

Trend

$\begin{array}{llll}\text { ym } & 15 & 0.001 & 0.002\end{array}$

Note: Results of seasonal (monthly) variables not shown.

Table 4: Random coefficient model results, top-20 global airlines, for other airline traffic measures

$$
\begin{array}{lll}
\text { Killed } & \text { Wounded } & \text { All casualties } \\
\text { \#sig Mean Std } & \text { \#sig Mean Std } & \text { \#sig Mean Std }
\end{array}
$$

$\begin{array}{llllllllll}\text { lak1 } & \mathbf{1 7} & \mathbf{- 0 . 1 7 8} & \mathbf{0 . 1 9 7} & \mathbf{1 7} & \mathbf{- 0 . 1 8 0} & \mathbf{0 . 2 0 0} & \mathbf{1 7} & \mathbf{- 0 . 1 8 0} & \mathbf{0 . 1 9 9} \\ \text { dl_x_ } & 3 & -0.003 & 0.020 & 1 & -0.004 & 0.021 & 3 & -0.004 & 0.024 \\ \text { l_x_1 } & 2 & -0.007 & 0.020 & 4 & -0.001 & 0.021 & 4 & -0.005 & 0.017 \\ \text { dluus } & 7 & -0.094 & 0.241 & 6 & -0.066 & 0.226 & 6 & -0.079 & 0.228 \\ \text { luus1 } & 3 & -0.001 & 0.066 & 4 & -0.010 & 0.085 & 3 & -0.003 & 0.070 \\ \text { sars } & 1 & -0.004 & 0.073 & 1 & -0.001 & 0.088 & 1 & -0.004 & 0.079 \\ \text { drop10 } & 1 & 0.074 & 0.433 & 1 & 0.074 & 0.426 & 1 & 0.074 & 0.431 \\ \text { inc10 } & 4 & -0.003 & 0.119 & 5 & -0.002 & 0.120 & 5 & -0.003 & 0.120 \\ \text { d911 } & \mathbf{1 0} & \mathbf{- 0 . 0 5 6} & \mathbf{0 . 1 0 4} & \mathbf{1 1} & \mathbf{- 0 . 0 5 7} & \mathbf{0 . 1 1 0} & \mathbf{1 1} & \mathbf{- 0 . 0 5 7} & \mathbf{0 . 1 0 8} \\ \text { diraq } & 1 & -0.025 & 0.066 & 1 & -0.026 & 0.068 & 1 & -0.026 & 0.068 \\ \text { dgulf } & 1 & -0.001 & 0.041 & 2 & -0.001 & 0.042 & 2 & -0.002 & 0.041 \\ \text { ym } & \mathbf{1 5} & \mathbf{0 . 0 0 1} & \mathbf{0 . 0 0 2} & \mathbf{1 6} & \mathbf{0 . 0 0 1} & \mathbf{0 . 0 0 2} & \mathbf{1 6} & \mathbf{0 . 0 0 1} & \mathbf{0 . 0 0 2}\end{array}$

Note: The “_x_” in dl_x_and 1_x_1 stands for killed, wounded, and all casualties in the respective equations. Results of seasonal (monthly) variables not shown. 


\section{Size effects}

To illustrate size effects, Table 5 records the coefficient estimates for the passenger load factor ( $p l f$ ) model for the top-20 global airlines, with the terror variable using the number of people killed in terror events. (For convenience, the 11 monthly estimates have been omitted from the table.) In this specification, various violence indicators and economic proxies are statistically significant, suggesting that they do influence the passenger load factor-the share of passenger kilometers flown as a percentage of seat kilometers available. The dependent variable is the change in the logarithm of the passenger load factor ( $d l p d f)$.

The first significant factor is the prior-month logarithm of the level of plf (lplf1): The higher the prior-month plf, the more pronounced the percentage decline in $p$ If to the next month, and vice versa. In other words, the more unusual any one month's aberration, the more the next month's plf is likely to get "pulled back" to trend. This effect is in addition to the overall rising trend $(\mathrm{ym})$ itself and to seasonality effects (not shown in the table) and simply means that inertial forces are by far the overriding factors accounting for month-to-month passenger load factor changes in the ordinary course of the airlines' business. None of this comes as a surprise: The statistical estimation merely provides a quantification of these effects (as well as a check on these intuitions).

The factors that are intrinsic to the airline business (inertia, trend, and seasonality) are amplified by external variables. U.S. unemployment is statistically significant but only in its prior-month variant, luus1. A worsening unemployment number in any one month adversely affects changes in the growth rate in the passenger load factor in the follow-on month. This, also, is as expected. In contrast, the $+/-10$-percentage point changes in the S\&P500 index (inc10 and drop10) do not appear to work well, statistically. The drop10 variable has a negative coefficient, as might be expected, but is not statistically significantly different from zero. The inc10 is statistically significantly, and strongly so, but has the "wrong" sign, suggesting that a drastic increase in the index reduces the plf growth rate that month. Although one can rationalize this result, it seems counterintuitive. The coefficient value, however, is small in size $(-0.061)$ and in any case affects a mere four months of data (1982:09; 1991:02; 1998:11; and 2009:04). The SARS variable is statistically insignificant. As discussed, despite its pandemic classification, in effect it was an epidemic, primarily affecting the Pacific/Asian airlines in our sample and not showing an effect in the whole sample of the top-20 global airlines.

More important for our purposes, the growth in the passenger load factor in any given month is influenced in a statistically significant way by the number of people killed in prior-month terror events (lkill1). As expected, the coefficient is negative, which means that an increase in the number of terror-related killings reduces the follow-on month growth rate in the passenger load factor, and vice versa (fewer terror killings are associated with higher load factors).
In a similar manner, the two wars (diraq and dgulf) exert statistically significant adverse effects on passenger load factors for each month in which the wars were in the combat stage. Finally, the coefficient for the 9/11-event is strongly statistically significant but comes out with a positive sign. This may appear puzzling - why would 9/11 have led to an increase in the plf growth rate?-but recall that the plf is the ratio of passengers carried to available seat capacity. Unquestionably, air kilometers traveled and passengers carried (pc) declined in response to 9/11 [the relevant coefficients from those models are $-0.062(\mathrm{t}=-3.9)$, and $-0.025(\mathrm{t}=-2.1)]$ but, as all travelers know, airlines responded by withdrawing aircraft from service, or using smaller aircraft, and packing their remaining aircraft with more passengers. In a word, efficiencies increased, as shown with rising passenger load factors. Upon individual inspection of the plf charts for each of the top-20 airlines, it becomes clear, however, that increasing plf efficiencies are part of a long-term trend, particularly for the U.S.-based airlines, so that this

9/11-related effect is not apparent in an unambiguous manner. Only the statistical modeling and estimation reveals that such an effect exists. However, at 0.018 , the size of the 9/11-coefficient is not large. It is, in fact, smaller than are the coefficients of the two wars.

Additional to short-term effects on month-to-month growth rates, the mathematics of the model permits one to derive long-term relationships in the data that determines the log-levels of plf. This can be computed by setting the log-level values equal to their lagged values, which makes the change variables equal to zero and drops out the lag-variables. With coefficients rounded to the third decimal place and omitting the seasonal factors, the long-term relationship then can be written as

(1) $0=-0.265$ lplf -0.004 lkill -0.041 luus -0.001 sars -0.010 drop10 -0.061 inc10 + 0.018 d911 -0.053 diraq -0.020 dgulf +0.000 ym +1.215 .

Solving for lplf gives

(2) $\quad$ lplf $=4.579-0.016$ lkill -0.154 luus -0.006 sars -0.038 drop10 -0.230 inc10 + 0.070 d911 - 0.199 diraq -0.076 dgulf +0.000 ym.
Table 5: Top-20 global airlines, monthly, 19802007

$\begin{array}{lcc}\text { *lplf1 } & \mathbf{- 0 . 2 6 5} & -\mathbf{3 2 . 0} \\ \text { dlkill } & 0.001 & 0.6 \\ \text { *lkill1 } & \mathbf{- 0 . 0 0 4} & -3.0 \\ \text { dluus } & -0.042 & -1.4 \\ \text { *luus1 } & \mathbf{- 0 . 0 4 1} & \mathbf{- 6 . 1} \\ \text { sars } & -0.001 & -0.2 \\ \text { drop10 } & -0.010 & -1.6 \\ \text { *inc10 } & \mathbf{- 0 . 0 6 1} & -\mathbf{7 . 7} \\ \text { *d911 } & \mathbf{0 . 0 1 8} & \mathbf{6 . 1} \\ \text { *diraq } & \mathbf{- 0 . 0 5 3} & -\mathbf{5 . 9} \\ \text { *dgulf } & \mathbf{- 0 . 0 2 0} & \mathbf{- 4 . 1} \\ \text { *ym } & \mathbf{0 . 0 0 0} & \mathbf{3 . 4} \\ \text { *cons } & \mathbf{1 . 2 1 5} & \mathbf{3 0 . 2}\end{array}$

Note: Seasonals omitted. 
The interpretation is that the immediate, short-term effect of a $1 \%$ increase in the growth of the number of people killed in global terror events increased growth of the passenger load factor of our top-20 global airlines by $0.001 \%$ (the dlkill coefficient in Table 5), while in the long-term every 1\% increase in the number of people killed decreased the passenger load factor ratio by $0.016 \%$ (the lkill coefficient in equation 2).

Because the coefficients for lkill and luus in equation (2) both refer to percentage changes, they may be compared to each other. Thus, the effect of a $10 \%$ increase in the U.S. unemployment rate (for instance, from 5.0 to 5.5 percent) exerts an effect about 10 times as strong $(0.154 / 0.016=9.625)$ than would a $10 \%$ increase in the number of people killed in terror events (for example, from 50 to 55). More important than killings per se are the event shocks: The Persian Gulf war reduced the passenger load factor for the top-20 global airlines by about $0.08 \%$ per month of war. Similarly, the shock of the Iraq war was about $-0.2 \%$ on plf. These coefficients are small in size.

Summary and conclusion

This research aimed to undertake a quantitative study of the effect, if any, of largescale violence in the form of terror and war on global air traffic, while taking account of confounding shock factors such as economic and financial crises, pandemics, or natural catastrophes. We excluded from consideration natural catastrophe-related effects on international scheduled air traffic. (They are always localized effects and cannot be expected to affect global air traffic.) The empirical work involved acquiring ICAO data on airline traffic and GTD data on terror events. This saw considerable practical problems and concern over the quality and consistency of the data. The ICAO data came to more than 370,000 observations; the terror data to more than 87,000 cases. We added economic, financial, and other data as well.

Constructing panels of data produced seemingly reasonable results. The empirical tests suggest that the pandemic variable (SARS) is never relevant at a global level. Statistically, SARS acts more like an epidemic through its effects on airlines in Asia. The economic and financial variables exert complex effects: For the top-20 airlines, absolute international scheduled air traffic measures (ak; pc) are not affected by unemployment but are affected by a fall in the S\&P500 index, whereas relative air traffic measures (plf; wlf) are affected by unemployment and the S\&P500 index. In regard to measures of violence (terror and war), the one-off 9/11-event is fairly consistently relevant for about half of the top-20 airlines, and the Iraq war somewhat more than the Gulf war. We observed considerable statistical mingling of the effects of specific shocks on specific airlines that, once amalgamated into the larger sample, appears to signal results that may not in fact be justified: Building up a joint sample from diverse individual airlines may yield misleading results, an outcome which may cast some doubt on the findings in the aggregate studies that tend to dominate the literature.

\section{Notes}

Jurgen Brauer is Professor of Economics at the Hull College of Business, Augusta State University, Augusta, GA, USA. The corresponding author, he may be reached at<jbrauer@aug.edu>. J. Paul Dunne is Professor of Economics at the School of Economics, University of Cape Town, Cape Town, South Africa. We thank the Arsenault Family Foundation for financial support to make this study possible. The study was carried out in behalf of Economists for Peace and Security (EPS), USA, from whom the full version of this research may be requested. We thank a reviewer for very helpful comments.

1. This article is a much shortened version of a commissioned study in which we also consider a larger sample of 443 airlines (Brauer and Dunne, 2011). The full study is available upon request from Thea Harvey <theaharvey@epsusa.org>.

2. There are other studies on 9/11 and the airline industry: Guzhva (2008), e.g., finds that the long-term effects were considerably smaller than the short-term ones and that the airlines were not equally affected. He also finds that the pricing of airline stocks was much less accurate for smaller airlines than for larger ones. A number of other papers consider the stock market effects, for example Gillen and Lall (2003).

3. In our final models, we excluded variables for natural catastrophes (earthquakes, hurricanes, volcanic eruptions, etc.). The reason is that natural catastrophes always are localized events, not much affecting global air traffic. When modeling for specific airlines in specific regions, however, it may well be appropriate to take account of natural catastrophes.

\section{A data request made to IATA in late 2008 was not fulfilled.}

5. Note that in this article, we do not study (1) domestic air traffic, (2) nonscheduled, e.g., chartered, air traffic, or (3) airfreight carriers' traffic, such as FedEx, UPS, or the cargo subsidiaries of the major passenger airlines.

6. For details, see Brauer and Dunne (2011).

7. An attempt by Enders, Sandler, and Gaibulloev (2011) to sort through the GDT dataset of, at the time, 82,536 events led, first, to the exclusion of about 18,000 events as not meeting the definition of terror and, second, to the classification of a further 7,000 events as “unknown,” leaving 46,413 domestic and 12,862 transnational events in their rendition of the GTD dataset. 


\section{References}

Brauer, J. and J.P. Dunne. 2011. "Effects of Large-Scale Violent Events on the Demand for International Scheduled Air Traffic.” Report. Annandale-on-Hudson, NY: Economists for Peace and Security.

Enders, W. and T. Sandler. 2012. The Political Economy of Terrorism. $2^{\text {nd }}$ ed. Updated and revised. New York: Cambridge University Press.

Enders, W., T. Sandler, and K. Gaibulloev. 2011. "Domestic versus Transnational Terrorism: Data, Decomposition, and Dynamics.” Journal of Peace Research. Vol. 48, No. 3, pp. 319-337.

Gillen, D. and A. Lall. 2003. "International Transmission of Shocks in the Airline Industry.” Journal of Air Transport Management. Vol. 9, No. 1, pp 37-49.

Guzhva, V.S. 2008. “Applying Intervention Analysis to Financial Performance Data: The Case of US Airlines and September 11th.” Journal of Economic Finance. Vol. 32, pp. 243-259.

Ito, H. and D. Lee. 2005a. "Comparing the Impact of the September 11th Terrorist Attacks on International Airline Demand.” International Journal of the Economics of Business. Vol. 12, No. 2, pp. 225-249.

Ito, H. and D. Lee. 2005b. “Assessing the Impact of the September 11 Terrorist Attacks on U.S. Airline Demand.” Journal of Economics and Business. Vol. 57, No. 1, pp. 75-95.

Liu, H. and J. Zeng. 2007. "Airline Passenger Fatality and the Demand for Air Travel.” Applied Economics. Vol. 39, pp. 1773-1781.

Rupp, N.G., G. Holems, and J. DeSimone. 2005. “Airline Schedule Recovery after Airport Closure: Empirical Evidence Since September 11.” Southern Economic Journal. Vol. 71, No. 4, pp. 800-820. 